\title{
A Comparative Study of the Morphology and Behaviour of Granular Haemocytes of Arthropods
}

\author{
M. H. Ravindranath \\ Department of Zoology, University of Madras, Chepauk,
}

Tamil Nadu-600005, India

Received May 17, 1976

Although Jones' (1962) classification of haemocytes of insects is found suitable for the purposes of a common classification of arthropod haemocytes (Ravindranath 1973, 1974a, 1974b, 1975a, Sherman 1974), there appears to be some ambiguity in the classification with reference to characterization of granular haemocytes and plasmatocytes. Jones' classification is based on distinguishing the cell types using morphological criteria alone. As this criterion was not distinguishing plasmatocytes and the granular haemocytes, Arnold (1966) sought to a functional criterion, namely the amoeboid movement. Though this criterion appeared to have solved a long standing confusion regarding these two cell types (Price and Ratcliffe 1974), the frequent reports (Arnold 1970, 1972, Ravindranath 1974a) that granular haemocytes are also amoeboid similar to plasmatocytes rule out the possibility of distinguishing these two cell types under normal conditions. It is felt that a study of these cells under different physiological and pathological conditions of the animal may provide some valid conclusions. In the present study, the morphology and behaviour of granular haemocytes of different non-insect arthropods in their wet preparations are compared. The feasibility of a common classification for haemocytes of arthropods and the individuality of granular haemocytes are elucidated.

\section{Materials and methods}

Animals investigated in the present study include specimens of mole-crab, Emerita asiatica, isopod, Ligia exotica, scorpion, Palamnaeus swammerdami and millipede Spirostreptus asthenus. Only intermoult forms (ovigerous females in mole-crabs) were used throughout the investigations. Terrestrial animals were prechilled by incubating in the ice chamber of the Frigidaire for about ten minutes. The chamber temperature was maintained at $10^{\circ} \mathrm{C}$. Marine animals were prechilled by immersing them in sea water at a temperature of $10^{\circ} \mathrm{C}$ for ten minutes. Prechilling is known to prevent or delay the degranulation and clumping of haemocytes (Ravindranath 1975a) and melanization of the haemolymph (Jones 1962).

By asceptic technique throughout, drops of whole blood, obtained by cutting the first walking leg, were placed on physiologically clean microscopic slide and covered quickly with equally clean No. 1 cover-slips. Observations were made with a phase-contrast microscope at room temperature. Sequential photographic records were made once in two minutes, with reference to the haemocytes of $E$. 
asiatica. $0.1 \%$ aqueous solutions of toludine blue and bromophenol blue were used as supra vital dyes.

\section{Observations}

\section{General}

The haemocyte types that met within the scorpion, the isopod, and the molecrab were described elsewhere (Ravindranath 1974a, 1974b, 1975a, 1975b). The haemocytes of the millipede, Spirostreptus asthenus, though generally conform to haemocyte types met within another millipede, Thyropygus poseidon (Ravindranath 1973), they differ from the haemocytes of latter in some respects. A cell type comparable to oenocytoid is wanting. The morphology of granular haemocyte is similar to its counterpart met within the scorpion, and the crustaceans. The granular haemocytes are the most abundant cell type among the haemocyte types of $E$. asiatica and $S$. asthenus. This cell type, in all these animals, is exceedingly variable in form. Usually they are ovoid, with abundant refractile, bacilliform granular inclusions, masking the nucleus (Fig. 1) and fit the description of a typical granular haemocyte (Millara 1947, Hoffmann 1967). The refractile granules stain blue with aqueous bromophenol blue; with toluidine blue the granules were colourless and remained refractile initially but after loss of refractility they stained metachromatically. The granules of the cells dissolved quickly in the aqueous solutions of the dyes.

\section{Behaviour of granular haemocytes on glass slides}

An interesting and a common feature observed among the granular haemocytes of the different arthropods (both normal and prechilled) is their tendency to spread on glass slides. During such spreading, the cell exhibits fan like ectoplasm with well developed version of filopodia. Such flattened peripheral cytoplasm is prominent in S. asthenus (Fig. 2), E. asiatica (Figs. 9-11) and P. swammerdami (Fig. 6 in Ravindranath 1974a). The granules and vacuoles if present are restricted to endoplasm. A striking uniformity in all such cells is that such ectoplasm with filopodia forms only after the loss of refractility of granules.

In the present study, stages of formation of ectoplasm was traced in prechilled E. asiatica (Figs. 6-11). The ectoplasm was not observed till six minutes after collection of blood. Soon after the loss of refractility of granules, the ectoplasm spreads in one direction giving the cell, a triangular outline. The ectoplasm spreads further, as the granules disappear and vacuolar droplets form.

When another cell is present in the vicinity, the fine ectoplasmic projections facilitate cell contact, adhesion and also agglutination.

In all these animals investigated in this study, vacuole formation is indicative of secretory activity is assessed by morphologically discernible phases of elaboration, accumulation, maturation and extrusion of vacuolar droplets. Other cell types do not exhibit discernible signs of secretory activity though the plasmatocytes possessed vacuoles. The vacuolar droplets observed in adiphohaemocytes appear to be permanent inclusions. 

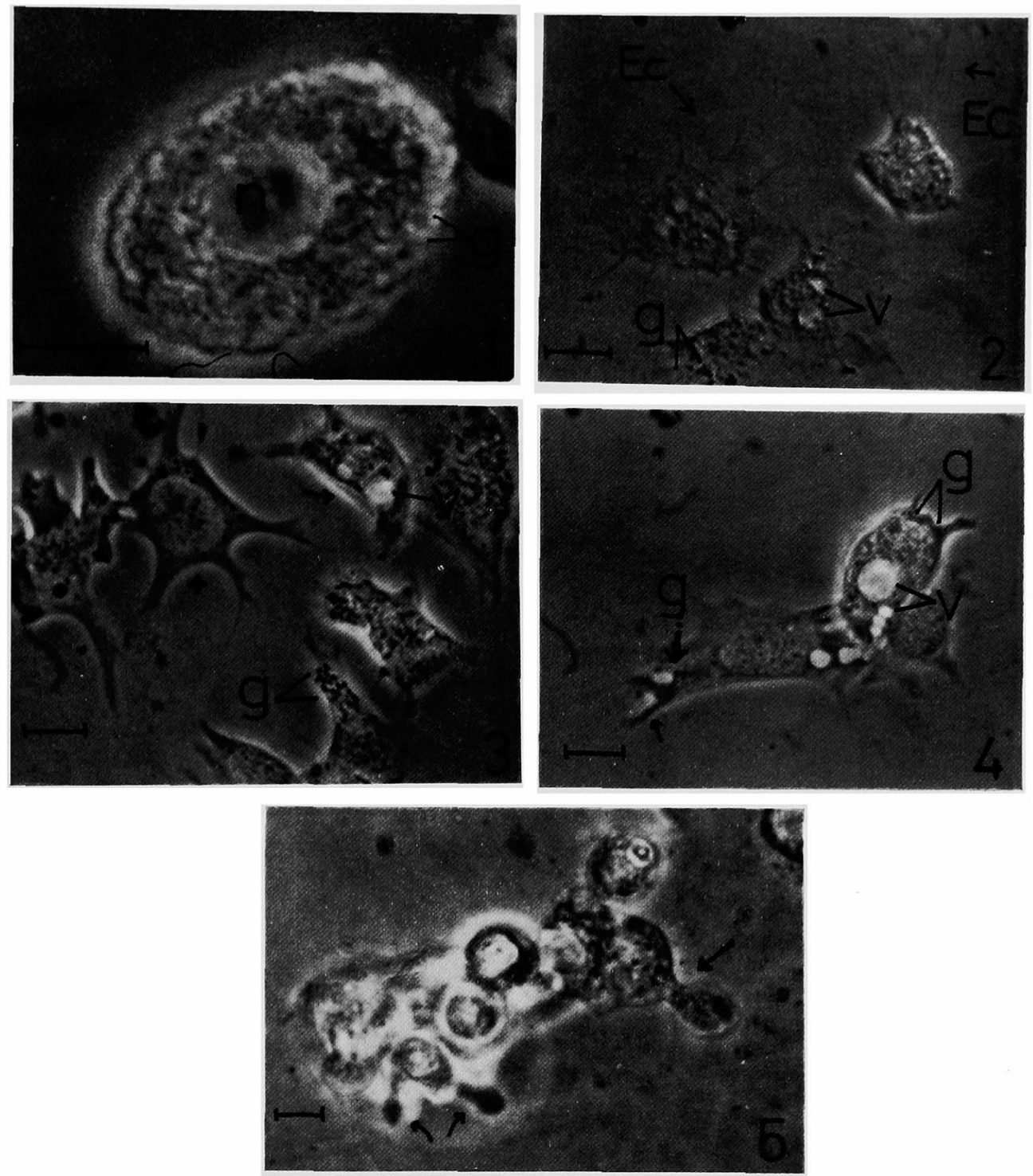

Figs. 1-5. Granular haemocytes. Reference lines indicates $10 \mu .1$, typical granular haemocytes of Emerita asiatica. n: nucleus, g: refractile granules. 2, granular haemocytes of Spirostreptus asthenus, well spread on glass slide, with ectoplasm (EC) showing well-developed filopodia (arrows), v: vacuole, g: granule. 3, arrow indicates the vacuolar droplet (v) in an amoeboid granular haemocyte of Palamnaeus swammerdami, plus indicates an agranular cell. 4, granular haemocytes of Palamnaeus swammerdami. Arrow indicates the mode of extrusion of vaculoar droplets in a granular haemocytes. g: granules, v: vacuole. 5, granular haemocytes of Ligia exotica exhibiting clasmatosis (arrows).

Intracellular relationships and general characteristics of vacuolar droplets in granular haemocytes

A perusal of the entire wet film preparation of blood sample of different animals reveals that many but not all of the granular haemocytes contain one or more pro- 
minent clear vacuolar droplets of variable size and distribution in the cytoplsam. Their disposition within the cytoplasm is dependent upon endoplasmic streaming which appear to push them from one region of the cell to another and into intimate relationships with each other, with the nucleus and with ectoplasmic region. A most intimate and characteristic spatial interrelationship exists between the droplets and the refractile granules. Usually the droplets assume the shape of spheres indicating that they may have relatively high surface tension and a greater physical consistence than the endoplasm. Continuous change in shape of the vacuolar droplets during endoplasmic streaming and degranulation suggest the fluidic nature of the contents. The cells were observed to be motile during formation of droplets (Fig. 3).
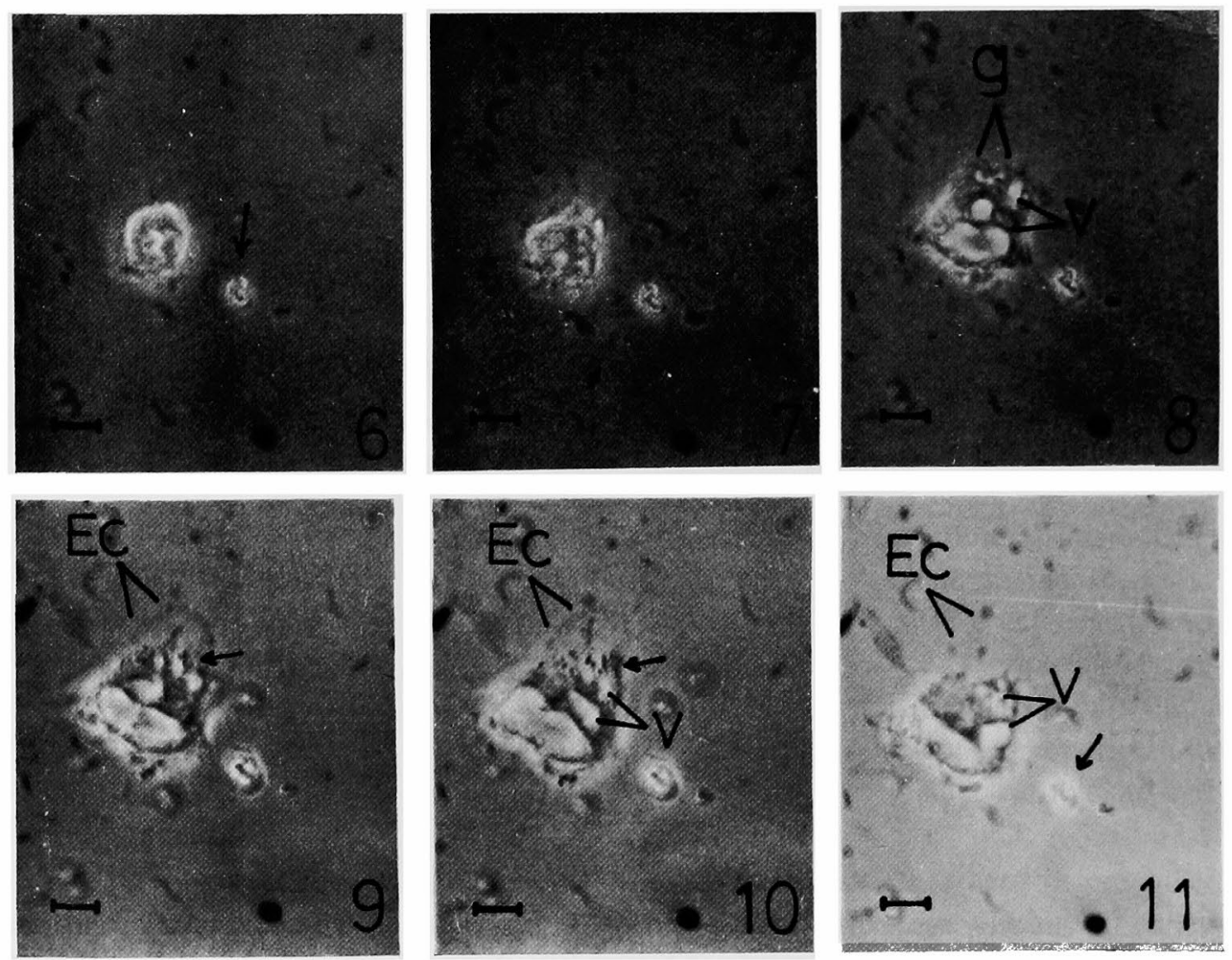

Figs. 6-11. Photographic records of granule-dependent formation of vacuoles and clasmatosis in granular haemocytes of Emerita asiatica. Reference lines indicate $10 \mu$. Arrows in Figs. 6 and 11 show the pinched of cytoplasm with refractile granules. Arrows in Figs. 9 and 10 indicate granular caps over vacuolar droplets. g: granule, v: vacuole, EC: Ectoplasm.

\section{Elaboration and maturation of the vacuolar droplets}

The vacuolar activity of the haemocytes appears to be temperature dependent. In E. asiatica, it was observed that the activity occurs at a slower rate in animals subjected to prechilling at $10^{\circ} \mathrm{C}$ in those immersed in the water at room temperature. Photographic records made of haemocytes in a prechilled animal clearly indicate the intimate association between the granules and the vacuoles. 
At zero minute (Fig. 6): The cell was typical in appearance. The refractile granules were masking the nucleus. No vacuolar droplets were observed. The cell was motile.

At three minutes (Fig. 7): Amidst refractile granules one or two spherical droplets, slightly larger than the granules were present. Such droplets, when first seen and afterwards, bore no special topographic relation to the nucleus.

At six minutes (Fig. 8): The granules lose their refractility. The vacuolar droplets either increase in size or number. Granules move and aggregate around vacuolar droplets.

At nine minutes (Fig. 9): The non-refractile granules form a cap over small vacuolar droplets.

At 12 minutes (Fig. 10): The individual vacuolar droplets increased in size. Endoplasmic streaming occasioned some aggregation of the droplets. The droplets fused, forming larger and prominent but highly irregular shaped masses which were unstable. Other droplets derived by more complete fusion of smaller ones formed discrete spherical ones, there to five micra in diameter, which were stable for some time.

At 15 minutes (Fig. 11): The various sized droplets had all become fused to form a reduced number of rather prominent droplets of irregular form. The granules continued to maintain a close association with the surface of the fusion droplets.

The viability of the cell in subsequent minutes depends on the mode of extrusion of vacuolar droplets. If the droplets liberate their contents within the cell, as it may occur when the cell is under the influence of other surrounding cells (Ravindranath 1975a), the cytoplasm lyses and the nucleus undergoes pycknosis.

\section{Extrusion of vacuolar droplets}

Unless cell death intervenes, the contents of the droplets elaborated by the granular haemocyte are usually extruded from the cell. The phase of extrusion of the droplets into the plasma is a rapid process. The extrusion process is not polarized in these cells. Liberation of contents occurs while the cells are moving and also when they are quiescent. Droplets extruded by the granular haemocytes of these animals, lose their identity almost immediately upon entering the plasma (Fig. 4).

Whether the phases of elaboration, maturation and extrusion of the vacuolar droplets is cyclical or not, could not be investigated in thin wet preparations, for the cells do not remain viable for long.

\section{Clasmatosis}

A feature of interest observed in the present study, is clasmatosis of granular haemocytes. The term clasmatosis was selected by Ranvier (1890) to designate the phenomenon of breaking off bits of cytoplasm of reticulo-endothelial cells in vertebrates. Photographic records made during phases of formation of vacuolar droplets in E. asiatica (Figs. 6-11) show that clasmatosis in granular haemocytes occur before any visible signs of the droplets formation could be seen. The observed phenomenon may not be due to compression with the coverslip is confirmed by examining blood samples without coverslips. No anticoagulants were used in 
this study. Moreover the scissors used in the study was previously cleaned. Therefore the possibility of the phenomenon being an artifact, induced by contaminants, is ruled out. The cytoplasmic bits pinched off from the cells always carried few refractile granules. No degranulation or vacuolization is observed in such bits (Figs. 6-11). The phenomenon of breaking up of cytoplasm and the broken up bits of cytoplasm in haemolymph are more common in prechilled animals than in normal animals. Granular haemocytes of scorpion and isopod (Fig. 6) also exhibit definite signs of clasmatosis. The cytoplasmic bits do not show any kind of pseudopodia, motility or spreading.

\section{Discussion}

The present study, together with previous observations enables unambiguous characterisation of the granular haemocytes of arthropods. The characteristic

Table 1. Comparison of granulocytes of arthropods ${ }^{1}$ and molluscs ${ }^{2}$

\begin{tabular}{|c|c|c|}
\hline \multirow{2}{*}{ Characters } & \multicolumn{2}{|c|}{ Granular heamocytes or leucocytes } \\
\hline & Arthropod & Mollusc \\
\hline Origin & Mesenchymatous & Mesenchymatous \\
\hline Size and shape & $\begin{array}{l}\text { Polymorphic with bizarre } \\
\text { forms }\end{array}$ & $\begin{array}{l}\text { Polymorphic with bizarre } \\
\text { forms }\end{array}$ \\
\hline Motility & Active, amoeboid & Active, amoeboid \\
\hline Behaviour on glass sildes & $\begin{array}{l}\text { Spreads-differentiates into } \\
\text { ecto and endoplasm- } \\
\text { ectoplasm with well } \\
\text { developed filopodia }\end{array}$ & $\begin{array}{l}\text { Spreads-differentiates into } \\
\text { ecto and endoplasm- } \\
\text { ectoplasm with well } \\
\text { developed filopodia }\end{array}$ \\
\hline $\begin{array}{l}\text { Clasmatocytic } \\
\text { (fragmentation of cytoplasm) }\end{array}$ & Yes & Yes \\
\hline \multicolumn{3}{|l|}{ Granules } \\
\hline i) Size & $0.2 \mu$ & $0.2 \mu$ \\
\hline ii) Movement & Brownian & Brownian \\
\hline $\begin{array}{l}\text { iii) Phase contrast } \\
\text { appearance } \\
\text { (when fresh) }\end{array}$ & Refractile & Refractile \\
\hline iv) In thin wet films & Loses refractility & Loses refractility \\
\hline v) Affinity to acidic dyes & Acidophilic & Acidophilic \\
\hline vi) Affinity to basic dyes & $\begin{array}{l}\text { Basophilic } \\
\text { (atfer losing refractility) }\end{array}$ & Basophilic \\
\hline $\begin{array}{l}\text { vii) Associate with formation } \\
\text { of vacuolar droplets }\end{array}$ & Yes & Yes \\
\hline viii) Degranulates & Yes & Yes \\
\hline $\begin{array}{l}\text { ix) Transforms to agranular } \\
\text { condition }\end{array}$ & Yes & Yes \\
\hline $\begin{array}{l}\text { x) Ultrastructural } \\
\text { appearance in sections }\end{array}$ & Finger-print like & Finger-print like \\
\hline Phagocytic & Yes & Yes \\
\hline Bactericidal & Yes & Yes \\
\hline
\end{tabular}

1 Present paper, literature cited in it and Kollmann 1908.

2 Papers of Kollmann 1908 and Foley and Cheng 1972, and the literature cited in them. 
features of typical granular haemocytes is presented in Table 1. The granuledependent formation of vacuolar droplets of granular haemocytes calls to mind the secretory activity of granular leucocytes of vertebrates. The vacuolar contents do not cause any damage to cytoplasm and nucleus (Ravindranath 1975a). The electron microscopic observations of Bauchau and De Brouwer (1974) on granular haemocytes of Eriochier sinensis (Planche III Figs. a and b) reveal that the content may be insulated by a membrane.

Previous studies indicate that the secretory activity of the haemocytes may be cyclical. In Rhodnius, Wigglesworth (1956 p. 142) observed that the haemocytes "show definite signs of secretory activity just at the time when hormone of the thoracic gland, is being produced". In the same insect, Jones (1965 p. 287) reports that the haemocytes "are highly secretory throughout the entire fourth stadium and during the fasting period after ecdysis to the fifth stage". Jones (1965 p. 283) refers these haemocytes as plasmatocytes and describes that they contain "sharplyoutlined round, ovoid, or short rod-shaped, or tear-drop shaped granular inclusions (Plate 1, Figs. 5, 6, 14, 15). With dark phased microscopy, the edges of these inclusions are generally sharp black and the enclosed granular space bright. The cytoplasm often contains few (two) to many (about 32) round or irregular, clear, nonrefringent, watery, colourless vacuoles of various sizes (Plate 1, Fig. 11-13)." This description of the cytoplasmic inclusions of the "plasmatocytes", reveals beyond doubt that the cells involved in vacuolization are definitely the granular haemocytes (see also Ravindranath 1974a). It is evident that during or after degranulation a granular haemocyte cannot be distinguished morphologically from a plasmatocyte (Ravindranath 1974a). The difficulty in distinguishing plasmatocytes from granular haemocytes was also experienced by previous investigators (Arnold 1966, Price and Ratcliffe 1974, Ravindranath 1974a). Arnold (1966) distinguishes the plasmatocytes from granular haemocytes by their amoeboid movements but later finds that the granular haemocytes are also ameoboid (Arnold 1970, 1972). In scorpions, the granular haemocytes are shown to be amoeboid (Ravindranath 1974a, Fig. 8 and 9). Functional characteristics such as phagocytic and bactericidal potentials are also common to both cells (Neuwirth 1974, Paterson and Stewart 1974, Ratcliffe and Rowley 1974).

Another feature observed in the granular haemocytes is the phenomenon of cytoplasmic fragmentation. This phenomenon has been recorded previously in plasmatocytes of insects (Arnold 1966, Gupta and Sutherland 1966). The broken up bits of haemocyte cytoplasm are referred to as plastids i.e., an enucleate portion of cytoplasm (Yeager 1945, Arnold 1966). Once again the behavioural similarly between plasmatocytes and granular haemocytes indicates the difficulty in distinguishing the two cell types. An obvious question arising from these findings is whether plasmatocyte is a degranulating or degranulated granular haemocyte. It appears that in all probability that the plasmatocyte may not be a different cell type, but only the altered granular haemocyte.

The exact significance of such cytoplasmic fragmentation of granular haemocyte is not clear at present, although it calls to the mind clasmatosis of vertebrate leucocytes and mast cells on one hand and cytoplasmic fragmentation of blastoderm cells 
of scyphozoans and anthozoans (Mergner 1971) on the other. In vertebrates, the resultant products of clasmatosis was suspected to involve in blood coagulation and some investigators also consider it to be the morphological basis of antibody formation (see Jones 1955). Mergner (1971) opines that the cytoplasmic bits of blastoderm cells of cnidarians may form the nutritive substance of the developing blastula. Gupta and Sutherland (1966) have suggested that the cytoplasmic fragmentation in insect haemocytes is triggered by some internal factor. The present study indicates that the environmental factors can also promote clasmatosis.

Most of the characteristic features of the granular haemocytes of arthropods strongly resemble the characteristics of the granular haemocytes of molluscs (Kollmann 1908, Foley and Cheng 1972) (Table 1). The findings presented in the table suggest that the coelomic cells comparable to granular haemocytes of arthropods may occur in other invertebrates also. A comparative survey of the cell types found in coelomic fluid of different invertebrates may provide valid information regarding phylogeny of arthropod haemocytes.

\section{Summary}

The characteristics of granular haemocytes of four non-insect arthropods were compared. The refractile, bacilliform granular inclusions dissolve in aqueous solutions of dyes. On glass slides, the cytoplasm of the haemocyte becomes distinctly separated into agranular ectoplasm with well developed filopodia and granular endoplasm. The mode of formation of vacuolar droplets together with the association of granules with them suggests secretory activity of the haemocytes. Fragmentation of cytoplasm or clasmatosis is common feature of granular haemocytes from prechilled animals. The significance of clasmatosis is discussed.

The present study indicates that the plasmatocytes reported by previous workers may be the altered granular haemocytes. The characteristics of granular haemocytes of arthropods are compared with that of the granulocytes of molluscs.

\section{Acknowledgements}

I consider it my pleasant duty to express my deep gratitude to Professor Dr. K. Ramalingam for his interest, encouragement and support in this investigation. I thank Dr. M. H. Rajeswari-Ravindranath, Assistant Professor, Queen Mary's College, Mr. S. Paulraj, Mr. K. Ramalingam and Mr. P. Ravichandran (Research Scholars) for reading the manuscript and for improving it. Sincere appreciation is expressed to Dr. S. Raghukumar for taking practically all the photographs upon which the supporting observations were based.

\section{References}

Arnold, J. W. 1966. An interpretation of the haemocyte complex in stonefly, Acroneuria arenosa Pietet (Plecoptera: Perilidae). Canad. Ent. 98: 394 411.

- 1970. Haemocytes of the pacific beetle cockroach Diploptera punctata. Canad. Ent. 102: $830-835$. 
- 1972. A comparative study of the haemocytes (blood cells) of cockroaches (Insects: Dictyoptera: Blattaria), with a view of their significance in taxonomy. Canad. Ent. 104: 309-348.

Bauchau, A. and De Brouwer, M. 1974. Étude ultrastructurale de la coagulation de l'hémolymphe chez les crustaces . J. Microsc. (France) 19: 37-46.

Foley, D. A. and Cheng, T. C. 1972. Interaction of molluses and foreign substances. The morphology and behaviour of haemolymph cells of the American Crassostrea virginica, in vitro. J. Invert. Pathol. 19: 383-394.

Gupta, A. P. and Sutherland, D. J. 1966. In vitro transformation of the insect plasmatocyte in some insects. J. Insect physiol. 12: 1369-1375.

Hoffmann, J. A. 1967. Étude des hémocytes de Locusta migratoria L. (Orthoptere). Arch. Zool. Ext. Gen. 108: 251-291.

Jones, J. C. 1965. The haemocytes of Rhodnius prolixus stal. Biol. Bull. 129: 282-294.

Jones, O. P. 1955. Dedication to Doctor Hal Downey. Ann. N. Y. Acad. Sci. 59: 667-670.

Kollmann, M. 1908. Recherches sur les leucocytes et le tissue lympoide des invertebres. Ann. Sci. Natur. Zool. 8: 1-238.

Mergner, H. 1971. Cnidaria. In 'Experimental embryology of marine and fresh-water invertebrates'. Ed. Reverberi, G. North-Holland Publ. Co.

Millara, P. 1947. Contribution a l'etude cytologique et physiologique des leucocytes d'insects. Bull. Biol. France and Belgium 81: 129-153.

Neuwirth, M. 1974. Granular haemocytes, the main phagocytic blood cells in Calpodes ethlius (Lepidoptera, Hesperiidae). Can. J. Zool. 52: 738-786.

Paterson, W. D. and Stewart, J. E. 1974. In vitro phagocytosis by haemocytes of the American lobster (Homarus americanus). J. Fish. Res. Board Canada 31: 1051-1056.

Price, C. D. and Ratcliffe, N. A. 1974. A reappraisal of insect haemocyte classification by the examination of blood from fifteen insect orders. Z. Zellforsch. 147: 537-549.

Ranvier, L. 1890. Des Clasmatocytes. C. R. Acad. Sci. 110: 165.

Ratcliffe, N. A. and Rowley, A. F. 1974. In vitro phagocytosis of bacteria by insect blood cells. Nature 252: 391-392.

Ravindranath, M. H. 1973. The haemocytes of a millipede, Thyropygus poseidon. J. Morphol. 141 : $257-268$.

-1974a. The haemocytes of a scorpion, Palamnaeus swammerdami. J. Morphol. 144: 1-10.

- 1974b. The haemocytes of an isopod, Ligia exotica Roux. J. Morphol, 144: 11-22.

- 1975a. Effects of temperature on the morphology of haemocytes and coagulation process in

. the mole-crab Emerita (=Hippa) asiatica. Biol. Bull. 148: 286-302.

- 1975b. Effects of hydrogen ion concentration on the morphology and behaviour of haemocytes of Emerita asiatica. Biol. Bull. 149: 226-235.

Sherman, R. G. 1973. Ultrastructurally different haemocytes in a spider. Can. J. Zool. 51:11551159.

Wigglesworth, V. B. 1956. The function of the amoebocytes during moulting in Rhodnius. Ann. Sci. Nat. Zool. 18: 139-144.

Yeager, J. F. 1945. The blood picture of the southern army worm (Prodenia eridania). J. Agric. Res. 71: $1-40$. 